\title{
A IMPORTÂNCIA DA AFETIVIDADE NA RELAÇÃO PROFESSOR/ALUNO NA APRENDIZAGEM DA CRIANÇA COM TRANSTORNO DO ESPECTRO AUTISTA - TEA NA EDUCAÇAO BÁSICA
}

\author{
THE IMPORTANCE OF AFFECTIVITY IN THE TEACHER/STUDENT RELATIONSHIP IN THE \\ LEARNING OF CHILDREN WITH AUTISTIC SPECTRUM DISORDERS - ASD IN BASIC \\ EDUCATION
}

Deise Perussi ${ }^{1}$, Fábio José Antonio da Silva ${ }^{2 *}$

I Pedagoga pela Universidade Estadual de Londrina - UEL/PR.

${ }^{2}$ Doutorando em Educação Física pela Universidade Estadual de Londrina - UEL/PR

\section{Info}

Recebido: 06/2021

Publicado: $11 / 2021$

DOI: $10.37951 / 2358-260 X .2021 v 8 i 2.5799$

ISSN: 2358-260X

\section{Palavras-Chave}

Afetividade. Relação professor/aluno.

Transtorno do Espectro Autista. Educação

Inclusiva. Educação Básica

Keywords:

Affectivity. Teacher/Student. Autistic

Spectrum Disorder. Inclusive education.

Basic education.

\begin{abstract}
Resumo
Faz-se notória desde há algum tempo, a preocupação de pesquisadores, estudiosos e docentes com o processo educacional de crianças com Transtornos do Espectro Autista - TEA. O tema foi selecionado pela necessidade de evidenciarmos teoricamente, se a afetividade pode ser elemento fundamental a influenciar o desenvolvimento infantil da criança com Transtorno do Espectro Autista - TEA. O problema que deu origem a esta investigação e que impôs este estudo foram os seguintes questionamentos: como proporcionar a estudantes com TEA uma educação inclusiva de qualidade, que seja, ao mesmo tempo motivadora ao estudante enquanto impulsione seu desenvolvimento global? A busca por responder tais questionamentos se justifica por termos, na instituição onde atuamos como docente, alunos com Transtorno do Espectro Autista - TEA. Assim sendo, nosso objetivo consiste
\end{abstract} em conhecer, através da revisão da literatura específica, se a afetividade pode influir significativamente na aprendizagem das crianças com Transtorno do Espectro Autista - TEA. Buscamos subsídios teóricos em Wallon e Vygotsky tendo por objetivo confirmar ou negar a idéia de que a afetividade possa ser elemento fundamental a influenciar o desenvolvimento do aluno com TEA. Obtivemos a comprovação de que ensinando com afetividade, o docente conseguirá que seu aluno aprenda efetivamente.

\begin{abstract}
It has been known for some time the concern of researchers, scholars and teachers have been concerned about the educational process of children with Autistic Spectrum Disorders - ASD. The theme was selected because of the need to theoretically evidence whether affectivity may be a fundamental element influencing the child development of children with Autistic Spectrum Disorder - ASD. The problem that gave rise to this research and imposed this study was the following questions: How to provide students with ASD with a quality inclusive education that is at the same time motivating the student while driving their global development? The search to answer such questions is justified by the fact that, in the institution where we act as a teacher, students with Autistic Spectrum Disorder - ASD. Therefore, our goal is to know, through the literature review, if affectivity can significantly influence the learning of children with Autistic Spectrum Disorder - ASD. We sought theoretical support in Wallon and Vygotsky to confirm or deny the idea that affectivity may be a fundamental element influencing the development of students with ASD. We have obtained the proof that by teaching with affection, the teacher will get his student to learn effectively.
\end{abstract}

\section{INTRODUÇÃO}

Nossa Constituição Cidadã dita que "todos somos iguais perante a Lei”, portanto, na Instituição Escola, a equidade e a participação de todos os alunos deve ser a tônica aplicada para que não haja exclusão de quem quer que seja o escolar conforme teoriza Brasil (2019), no Art. 206 dessa Carta, registrando “os 
princípios da igualdade de condições para o acesso e permanência na escola e liberdade de aprender".

Nesse sentido é que, legalmente, coloca-se ênfase na Educação Inclusiva como capaz de conter e, até, de superar a exclusão a qual, comumente, é denominada fracasso escolar.

A história da Educação Especial perpassou momentos históricos difíceis que se iniciaram no menosprezo, passando pelo assistencialismo e integracionismo da criança "diferente".

No que diz respeito à inclusão efetiva da criança autista em geral, foco deste artigo, o processo muito mais se complexifica porque ela traz consigo, além das características diagnósticas inerentes ao autismo, outras tantas comorbidades e transtornos que podem vir a ser agregados a seu problema, tais como transtornos sensoriais, motores e emocionais, fazendo que cada uma dessas crianças tenha uma individualidade específica considerando-se suas necessidades educativas.

O tema foi selecionado pela necessidade de conhecermos, teoricamente, se a afetividade pode ser elemento importante a influenciar o desenvolvimento infantil da criança com TEA.

O problema posto é que, tendo alunos autistas onde trabalhamos, aconteceram questionamentos que almejamos responder através deste estudo, sendo eles: como proporcionar a esses estudantes uma educação inclusiva de qualidade, como impulsionar seus desenvolvimentos cognitivos, sociais, emocionais e pessoais?

O desejo de responder a esses questionamentos é que justifica a necessidade deste estudo, pois só assim poderemos oferecer a essas crianças um ensino mais condizente e coerente com as necessidades educativas delas, ao mesmo tempo em que se impulsionam seus desenvolvimentos cognitivo, social, emocional e pessoal.
Assim é que nosso objetivo consiste em conhecer, através da revisão da literatura específica, se a afetividade pode influir na aprendizagem das crianças com Transtorno do Espectro Autista - TEA.

A metodologia escolhida para desenvolver este estudo foi a revisão da literatura. Buscaremos subsídios teóricos em Wallon e Vygotsky tendo por objetivo positivar ou negar a idéia de que a afetividade possa ser elemento importante a influenciar o desenvolvimento do aluno com TEA. Além desses autores, buscaremos outros mais atuais que teorizam sobre o assunto na tentativa de aprofundar tais conhecimentos.

\section{O AUTISMO NO CONTEXTO ESCOLAR}

$O$ processo de aprendizagem infantil preocupa muitos estudiosos, tais como Duk e Silva, porque se trata do fundamento para toda a vida de todo estudante e da pessoa. Nesse sentido é que a Inclusão se torna essencial para nortear o desenvolvimento educacional da criança em geral, mas em especial, o daquela que apresenta alguma necessidade educativa diferenciada, vem daí o fato de evidenciarmos a palavra todo na primeira frase.

Este artigo que trata do aprendizado escolar da criança com Transtorno do Espectro Autista - TEA abordará a faixa educativa que compreende a primeira e a segunda fase da Educação Básica que são a Educação Infantil e o Ensino Fundamental, porque são nesses contextos que a criança autista começa a participar do processo escolar inclusivo efetivamente.

Impõe-se, portanto, definir o conceito de Inclusão Escolar, conceituar o que é autismo e, ao mesmo tempo, investigar teoricamente se o relacionamento afetivo havido entre professor e aluno autista influencia o aprendizado desse aluno de alguma forma, pois se pretende oferecer a esse estudante possibilidades práticas de uma educação inclusiva de 
qualidade que impulsione seu desenvolvimento cognitivo, social, emocional e pessoal.

Isso porque, faz-se notória, nas ultimas décadas, a preocupação da inclusão real de alunos com algum transtorno global de desenvolvimento na área educativa.

Em razão da problemática que cerca esses alunos é que este tema foi escolhido porque, sendo a instituição Escola considerada a grande difusora do conhecimento, espera-se dela que consiga alfabetizar esses alunos nas classes regulares conforme destacam os artigos 59 e 60 da LDBEN - Lei 9394/96, bem como as tantas outras legislações que foram criadas para que o processo de inclusão possa acontecer de fato e com qualidade.

\subsection{Síntese Histórica da Educação Especial e da}

\section{Inclusão}

A modalidade de Educação Especial, segundo Rotta et al

$$
\begin{aligned}
& \text { surgiu na Espanha, quando } \\
& \text { em 1550, Ponce de Léon, } \\
& \text { sentiu necessidade de } \\
& \text { atender crianças surdas e } \\
& \text { mudas, com dificuldades } \\
& \text { para aprenderem na escola } \\
& \text { que tinha por sistema, ser } \\
& \text { voltada a alunos ouvintes } \\
& \text { (2019, p. 94). }
\end{aligned}
$$

Ainda segundo Rotta et alli (2019), seguiram as reocupações iniciais de Ponce de Leon autores como: Pereire, Pestalozzi, Itard (primeiro a se preocupar cientificamente com a educação de indivíduos mentalmente limitados), Froebel, Séguin, Montessori, Binet, Claparede (que pregava a escola sob medida), Piaget (que propôs a estimulação às operações intelectuais das crianças).
Adler, autor que pregava a adaptação progressiva da criança no meio social a partir da escola e que teve seus trabalhos continuados por Wallon, Ajuriaguerra e Stamback. Estudos que, segundo Rotta et alli (2019, p. 96) "deram novos rumos ao enfoque pedagógico".

Ainda na teoria de Rotta et al (2019, p. 96) Lapierre e Aucouturier teorizavam serem

os problemas psicomotores, perceptivos, gnósicos, práxicos, psicoafetivos e sociafetivos constitutivos de dificuldades a serem vencidas por todas as crianças, porém, para as que apresentam dificuldades escolares a dificuldade é de difícil superação [...] (apud ROT'TA et alli, 2019, p.96).

Contudo, esses autores (ibidem) acreditam que "muitos desses problemas serão resolvidos se as técnicas pedagógicas usadas para as crianças desadaptadas forem aplicadas largamente no ensino normal".

Poppovic (em 1968) foi "o" estudioso que chamou a atenção para a

importância das técnicas psicológicas no estudo das dificuldades para a aprendizagem mostrando, ainda, a necessidade de uma avaliação neurológica da criança estabelecendo a "prontidão para a alfabetização" e o enfoque multidisciplinar para a aprendizagem (apud ROTTA, 2019, p.97). 
Significa dizer que numa educação que se

A trajetória exposta nesse breve resumo histórico só vem nos cientificar dos caminhos tortuosos pelos quais passaram alguns estudiosos interessados em saber como a criança aprende. Essa preocupação, após tanto tempo de reiterado fracasso escolar infantil do aluno "com necessidades educativas especiais", passou a ter como objeto de estudo exatamente aquelas crianças que não conseguiam aprender, de maneira que, nesse caminho é que se foi delineando uma luta social e cientifica em favor dos rumos históricos da Educação Especial no mundo a qual, continuamente, vem tendo acréscimos em seus capítulos, tanto no que diz respeito a políticas de ensino como às de aprendizagem, sendo que até o momento a Inclusão é o ápice que, conforme regula Brasil (2019 a, p. 5) "foi desencadeada em defesa do direito de todos os alunos de estarem juntos, aprendendo e participando".

\subsubsection{Inclusão Escolar}

De acordo com Góes (2010) dedicou-se intensamente a campos que, em sua época, denominava-se defectologia, ou seja, estudo de pessoas com deficiência ou transtornos de desenvolvimento (2019, p. 95). Sua preocupação, portanto, estava posta na inclusão dessas pessoas.

Assim, definir o que seja transtorno de desenvolvimento se faz necessário para melhor entendimento da teoria desse estudioso russo que foi "pioneiro no conceito de que o desenvolvimento intelectual das crianças ocorre em função das interações sociais e condições de vida" como afirma Machado (2019, p. 10).

Duk (2019, p. 12), afirma que "devemos identificar e abordar as dificuldades educacionais que emergem durante o processo ensino-aprendizagem" para podermos realizar uma abordagem metodológica mais coerente às necessidades reais de nossos alunos. denomine inclusiva, tanto as instituições escolares quanto os professores, devem se adaptar para oferecer aos alunos com necessidades educativas especiais e/ou diferenciadas uma educação que os inclua, efetivamente, em todos os espaços culturais e físicos, além de inclui-los em atividades pedagógicas apropriadas e com qualidade para que se impulsione o pleno desenvolvimento integral desses alunos.

O artigo 206, inciso I de nossa Constituição Cidadã estabelece a "igualdade de condições de acesso e permanência na escola a todos os alunos", garantindo em seu artigo 208 ser "dever do Estado a oferta do atendimento educacional especializado, preferencialmente na rede regular de ensino" (BRASIL, 2019a p. 7).

Mendes faz a colocação de que

pesquisadores norteamericanos identificaram que o termo "inclusão" apareceu na literatura por volta de 1990, como substituto do termo "integração" e associado à ideia de colocação de alunos com dificuldades prioritariamente nas classes comuns (2019, p. 391).

Todavia, o termo não se refere apenas e simplesmente em colocar os alunos juntos aos de mesma idade conforme critica de Mendes.

Mantoan, coloca que a inclusão é uma mudança de paradigma, isto é, antes o foco era integrar os alunos junto aos demais no ambiente escolar, mas na inclusão, a Escola se transforma e se adapta para atender o acesso à diversidade do alunado com deficiência. Por isso essa autora afirma que, para que 
uma escola seja inclusiva, "deve reconhecer e valorizar as diferenças" (2019, pp. 12, 14).

Brande \& Zanfelice reiteram o "desafio que as escolas enfrentam para exercitar adequações ambientais, curriculares e metodológicas para receber alunos com deficiências" (2019, p. 44).

Portanto, as teorias revisadas clarificam a questão de que inclusão significa mudança de metodologia, realizações de adaptações tanto de currículo como das práticas pedagógicas para atendimento à diversidade de alunos com necessidades educativas especiais.

\subsection{Conceituando Transtorno do Espectro Autista} - TEA

O Ministério da Saúde acredita que seja necessário, quanto à questão do que é o Transtorno do Espectro Autista - TEA, falar em autismos no plural, já que existe grande complexidade das questões envolvidas nas diversas formas de autismo que exigem que a ética do campo público seja ao mesmo tempo rigorosa e flexível, para dar acolhida a diferentes concepções sobre esse quadro (BRASIL, 2019 a, p. 29 30).

Ainda sobre esse assunto, Brasil ressalta que "o diagnóstico de Transtorno do Espectro Autista - TEA constitui uma descrição e não uma explicação”. (2019 a, p. 37).

Tanto é assim que, considerando a flexibilidade do tema, esse mesmo autor enfatiza que

as classificações devem estar sempre abertas ao aperfeiçoamento e somente adquirem sentido se utilizadas no contexto de um processo diagnóstico contínuo e complexo que coloque sempre em primeiro lugar a pessoa e não $\mathrm{o}$ seu transtorno

(BRASIL; 2019 a, p. 42).

Vygotsky, por tanto estudar essa categoria específica de pessoas chegou à conclusão de que "as leis gerais de desenvolvimento são iguais para todas as crianças", mas que, no que se refere "às crianças com alguma espécie de deficiência, devem ser oferecidos caminhos de ensino alternativos e com recursos especiais" (apud IVIC, 2019, p. 99).

Vygotsky não admite o foco do ensino pautado na deficiência da criança, mas sim em seu desenvolvimento sociocultural. Para ele, esse desenvolvimento é resultado das interações sociais qualitativas que a família e o professor possam possibilitar à criança. E ele se refere que a educação direcionada a essa criança deficiente seja a mesma realizada com a criança normal, e alerta para o fato de que a criança com deficiência mental pode não aprender o mesmo que as demais e nem no mesmo ritmo, mas que deve receber o mesmo ensino proposto àquelas e receber, também, a mesma preparação para a vida futura (apud IVIC, 2019, passim).

Spagolla suplementa tais afirmações ao considerar que "por ser o homem um ser, cuja intelectualidade e emoção fundem-se trazendo implicações no desenvolvimento educativo", necessário se torna realizar uma educação que considere a afetividade tal como entendia Vygotsky (SPAGOLLA, 2019, p. 4).

Numa perspectiva walloniana, Galvão, aponta que

os conflitos são propulsores do desenvolvimento humano, e o papel da afetividade nos diferentes estágios deste desenvolvimento sucede-se 
em fases com programáticos, as interações grupais necessárias para predominância afetiva e isso.

cognitiva, rupturas, contradições e conflitos que resultam da maturação e das condições ambientais, provocando alterações no comportamento infantil de modo geral (apud SPAGOLLA, 2019, p. 6).

Ou seja, ao interagir com o meio a criança expressa afetividade e é movida por ela enquanto vai se constituindo pessoa, levando Wallon a afirmar que ambas (afetividade e cognitividade) perfazem um par inseparável. Baseada no domínio desses conhecimentos é que a autora cita Wallon, para quem o docente deve ter aprofundamento teórico bastante em conhecer como a criança vai se constituindo pessoa, porque considera que

tais conhecimentos são valiosos instrumentos para a reflexão de como a escola pode desencadear múltiplas possibilidades para enriquecer $\mathrm{O}$ processo ensino-aprendizagem, suscitando novas formas de pensar a educação (apud SPAGOLLA, 2019, p.8).

Pelo exposto, fica claro que o professor deve conhecer como acontece o desenvolvimento da criança para poder, com propriedade, se pautar numa abordagem pedagógica que considere, incentive e exercite as dimensões emocional e afetiva no processo de ensino e de aprendizagem, com vistas a propiciar que o aluno se desenvolva globalmente ao se sentir valorizado, respeitado e capaz de aprender através de uma pedagogia que proporcione, além dos conteúdos
Souza (2014), respaldada nas teorias walloniana e vygotskyana, afirma que o professor deve criar laços afetivos com o aluno, ao objetivar desenvolver uma aprendizagem efetiva e significativa. Isso é o que todos os alunos necessitam e, em especial, os alunos com transtornos globais de desenvolvimento em cujo rol estão incluídos os alunos com Transtorno do Espectro Autista - TEA, foco desta pesquisa que, como dita a Lei, são iguais aos demais em direito. Diante dessas teorias vejamos a importância que a afetividade exerce sobre o desenvolvimento infantil.

\subsection{A afetividade como fundamental ao} desenvolvimento cognitivo e socioemocional do aluno

Wallon deixou-nos a expressão de que o homem é ser "geneticamente social" porque entende que, desde seu nascimento a criança já se encontra orientada para pessoas, exercitando, assim, sua expressividade emocional (apud GALVÃO, 2019, p. 15).

Para Galvão (2019, p.17) “existem várias linhas de pesquisa que tentam explicar a gênese das competências emocionais" e ela apresenta tais estudos como focados apenas nas expressividades faciais dos bebês.

Por isso essa autora afirma que para Wallon as fontes dos estados emocionais se ampliam e se complexificam com o tempo, sendo que a preponderância inicial das reações orgânicas e expressivas vai sendo substituída pelas imagens e impressões subjetivas, ou 
seja, desse processo resulta a atividade intelectual. (apud GALVÃO, 2019, p.22)

Diante dessa teoria se entende que a emoção tem importante papel na cognição e, portanto, no acesso à linguagem, devido haver imbricação entre os processos afetivos e cognitivos.

\subsubsection{Ressignificando o aprendizado do autista}

O escolar com Transtorno do Espectro Autista - TEA, como afirmado nas teorias citadas, aprende como as demais crianças, só que em ritmo diferente e a partir de metodologias alternativas. Impera assim, a demanda por profissionais docentes que atendam as necessidades desses alunos, levando Brasil a regrar o assunto

na Resolução $\mathrm{CNE} / \mathrm{CP} \mathrm{n}^{\circ}$ 1/2002, a qual estabelece Diretrizes Curriculares Nacionais para a Formação de Professores da Educação Básica, definindo que as instituições de ensino superior devem prever, em sua organização curricular, formação docente voltada para a atenção à diversidade e que contemple conhecimentos sobre as especificidades dos estudantes com deficiência, transtornos globais do desenvolvimento e altas habilidades/superdotação (BRASIL, 2019 a, p. 4)

Nosso grifo refere-se à ênfase que o governo concede à formação de professores para o alunado da educação especial como um todo.
Nesse sentido, explicitaremos as teorias afetivas propostas por Wallon e Vygotsky, porque este ultimo afirmou que

É por meio de outros, por intermédio do adulto que a criança se envolve em suas atividades. Absolutamente, tudo no comportamento da criança está fundido, enraizado no social. [E prossegue:] Assim, as relações da criança com a realidade são, desde o início, relações sociais (apud IVIC, 2019, p. 17).

Silva (2019), fundamentada em Wallon, coloca que a afetividade é um vínculo social, já que une professor e aluno e que, sendo assim, funciona como propulsora da aprendizagem.

Nesse contexto, para que o docente possa atender as necessidades educativas do TEA, além do domínio dos conhecimentos acadêmicos que deve ter sobre o assunto, ele deve possibilitar ao educando muitas situações de interações sociais, posto que a teoria vygotskyana assegura que, dessas interações resulta o desenvolvimento do escolar, haja vista o imbricamento dos processos cognitivos e afetivos como citado passim.

Silva alerta, ainda, que, se o professor é responsável por contribuir para a formação da personalidade do educando, ele tem que considerar a função da escola de formar a afetividade infantil, posto que o docente funciona como mediador da aprendizagem e, nesse sentido, precisa olhar e ouvir os apelos da criança (2019).

Já Wallon afirma que "o educador que se mantiver atento a essas manifestações da criança terá elementos extras para compreender e manejar o 
processo de aprendizagem" (apud GRATIOTALFANDÉRY, 2019, p. 39).

Amparado, também, em seus próprios estudos que comprovaram que "o meio é o portador dos significados profundos", Vygotsky concede relevância aos "processos externos como as interações socioafetivas, a cultura, as obras culturais, os instrumentos psicológicos e outros que [...] ao lado da memória ou da inteligência individual e natural, provocam conhecimentos" (apud IVIC, 2019, p. 22).

Para isso esse autor utiliza-se de sua teoria da Zona do Desenvolvimento Proximal que, em síntese, seria estimular o aluno a galgar patamares mais elevados de conhecimento do que aqueles de que já dispõe como fruto do seu potencial, mas que pode construir conhecimento superior (próximo).

Decorrente dessa teoria é que se depreende que, o aluno só interioriza aquilo que a realidade escolar lhe oferece como elemento capaz de transformar seu pensamento e sua memória. Assim sendo, a teoria do desenvolvimento de Vygotsky, assim como as teorias wallonianas sobre a afetividade, forneceram elementos essenciais para melhor compreendermos os fenômenos educativos no qual se incluem a afetividade, sua importância e seu papel no desenvolvimento do estudante (apud IVIC, 2019, passim).

Acerca do assunto interações socioafetivas, Silva teoriza que "nas relações que mantem com os adultos, a criança demonstra sua afetividade, seja de modo positivo ou negativo e esses aspectos dependem da relação que o adulto estabelece com ela" (2019).

$$
\text { Segundo Silva (2019, p. 8) “o afeto }
$$
proporciona uma relação baseada na confiança, no respeito, na admiração, e por isso eleva a autoestima da criança”. Ainda assegura essa autora que

$$
\begin{aligned}
& \text { uma vez a autoestima } \\
& \text { elevada, o aluno vai refletir o } \\
& \text { prazer de estar na escola, }
\end{aligned}
$$

sendo imperativo que pais e professores considerem a dimensão afetiva durante o processo de ensino e aprendizagem e cuidem da criança como um todo, pois a falta de afeto compromete a construção do conhecimento e influi no emocional da criança (2019, p. 95).

Por isso é que Wallon destaca a afetividade como fator central na construção do conhecimento e da pessoa, porque ele afirma que a expressão emocional precede e supera os recursos cognitivos (apud GRATIOT-ALFANDÉRY, 2019, p. 38).

Enfim, há que se considerar que

o movimento e agitação motora, normalmente reconhecida pela escola como sinal de problema de aprendizagem, baixo ou excessivo interesse, os quais, se analisados pela perspectiva walloniana, podem acrescentar entendimento às práticas escolares, pelo reconhecimento de que essa expressividade motora está indissociavelmente ligada ao desenvolvimento da linguagem, do pensamento e da percepção da criança (apud GRATIOTALFANDÉRY, 2019, p. 42). 
Simplificando, para Wallon e Vygotsky o docente deve manter os focos visual, auditivo e afetivo no aluno, com o que vai entender se está cooperando com o aprendizado da criança.

Outro autor que comunga das teorias wallonianas é Cunha, com cuja ideia concluímos esta exposição teórica, já que esse autor postula que "o afeto gerencia as relações com o saber, que perdurarão ao longo da vida não com as digitais do professor, mas com as marcas da amorosidade que possibilitarão ao aprendente conquistar sua autonomia" (2019, p. 23).

\section{CONCLUSÃO}

Nossa pesquisa nos trouxe a convicção da importância do afeto como recurso para os alunos, em geral, construírem saberes. No que diz respeito ao aluno com Transtornos do Espectro Autista - TEA, essa importância mais se fortificou, pois pudemos comprovar pelas teorias revisadas que a presença do afeto nos processos de ensino, de aprendizagem e nos relacionamentos professor/aluno influencia cognitiva e emocionalmente o desenvolvimento global da criança. Pudemos comprovar também, através do auxilio teórico em Wallon e Vygotsky, que uma metodologia afetiva pode influenciar a aprendizagem do aluno autista positiva e eficazmente.

No que diz respeito à nossa prática docente, as contribuições foram demasiado valiosas, pois aprendemos que nossa prática, não apenas influencia o aprendizado desse aluno, como também pode impulsionar negativamente esse aprendizado caso desconsideremos as teorias que sustentam que o aprendizado é consequência, não apenas do ensino, mas sim, do ensino que considere cada aluno como individuo único, cuja cognição e memória merecem atenção didático-pedagógicas alternativas e que, nesse caminho a ser percorrido, a afetividade se faça presente.
As teorias revisadas só fortalecerem nosso conhecimento inicial de que a afetividade pode influir significativamente na aprendizagem das crianças com Transtorno do Espectro Autista - TEA. Desse modo, podemos afirmar que nossos objetivos foram atingidos por considerarmos que metodologias alternativas fundamentadas na afetividade podem solucionar o impasse da não aprendizagem do aluno autista.

Além disso, entendemos que a educação do aluno com TEA necessita de mais estímulos, porque essa é a base de todo arcabouço de conhecimentos de uma pessoa que merece, como as demais, que a letra da Lei seja cumprida à risca, já que a equidade é direito fundamental que lhes é assegurado por diversas políticas brasileiras, assim como a inclusão.

Além de todo o exposto, entendemos com os estudos realizados que, apenas as metodologias afetivas e alternativas do professor não garantem a aprendizagem do aluno com TEA. Isso porque, o docente e o aluno precisam contar, também, com a participação e colaboração dos pais dos alunos e dos demais alunos da escola. Essa rede integrada de apoio e de afeto se faz muito importante porque o aluno se sentirá cercado pelo carinho e atenção de todos e, dessa maneira, se sentirá mais motivado à aprendizagem.

Sugerimos que os docentes tomem conhecimento dessas teorias para que assim, bem fundamentados teoricamente, possam desenvolver uma prática pedagógica mais coerente com as necessidades do aluno autista, da qual resultarão bons e significativos frutos.

Além de todo o ganho teórico sobre o assunto revisado, ainda pudemos conhecer que, historicamente, as teorias wallonianas estão presentes no Brasil desde os anos oitenta do século passado.

Portanto a afetividade é de importância fundamental no processo de aprendizagem dos alunos com TEA. Sugerimos, para trabalhos acadêmicos 
futuros, a apresentação de metodologias afetivas que possam atender esses alunos.

\section{REFERÊNCIAS BIBLIOGRÁFICAS}

BRANDE; Carla Andréa; ZANFELICE, Camila Cilene. A inclusão escolar de um aluno com autismo: diferentes tempos de escuta, intervenção e aprendizagens. Disponível em: http://www.rhemaeducacao.com.br/material/ material-

turma/9ae441ba87ce148e12351c8236bae3e2.pd f. Acesso: 07 abr. 2019.

BRASIL. Constituição da república federativa do Brasil de 1988. Disponível em: http://www.planalto.gov.br/ccivil 03/Constitu icao/Constituicao.htm. Acesso: 08 abr. 2019.

Política nacional de educação especial na perspectiva da educação inclusiva. (2008). Disponível em: http://portal.mec.gov.br/index.php?option $=$ co $\mathrm{m}$ docman\&view $=$ download\&alias $=16690$ politica-nacional-de-educacao-especial-naperspectiva-da-educacao-inclusiva05122014\&Itemid=30192. Acesso: 07 abr. 2019 a.

CARVALHO, Chayene Cristina Santos. Linguagem escrita e autismo: um estudo de caso em uma sala de aula regular em São Luís - MA. Disponível em: http://educere.bruc.com.br/arquivo/pdf2015/ 16799 9865.pdf.Acesso: 02 maio 2019.

CUNHA, Eugênio. O afeto tem a força de um sonho. Disponível em: https://www.eugeniocunha.com/artigo/70/oafeto-tem-a-forca-de-um-sonho. Acesso em: 03 maio 2019.

DUK, Cynthia. Educar na diversidade: material de formação docente. 3. ed. / edição do material Cynthia Duk. - Brasília: [MEC, SEESP], 2006.

GALVÃO, Isabel. Expressividade e emoção: ampliando o olhar sobre as interações sociais. Disponível em: http://www.revistas.usp.br/rpef/article/view/ 139590/134894. Acesso em: 12 maio 2019.

GÓES, Maria Cecilia Rafael de. Deficiência e educação: contribuições da abordagem histórico-cultural
IN Psicologia, educação e as temáticas da vida contemporânea. Marta Kohl de Oliveira, Teresa Cristina Rego e Denise Trento R. Souza (orgs.). Disponível em: https://edisciplinas.usp.br/pluginfile.php/3481 $\underline{860 / \mathrm{mod} \text { resource/content } / 2 / \text { Relacoes } \% 20 \text { en }}$ tre $\% 20$ desenvolvimento $\% 20$ humano $\% 20$ deficie ncia $\% 20 \mathrm{e} \% 20$ educacao.pdf. Acesso em: 04 maio 2019.

GRATIOT-ALFANDÉRY, Hélène. Henri Wallon. Tradução e organização Patrícia Junqueira. Disponível em: http://livros01.livrosgratis.com.br/me4686.pdf. Acesso em: 06 jun. 2019.

IVIC, Ivan. Vygotsky Lev Semionovich. Tradução: José Eustáquio Romão. Disponível em: http://livros01.livrosgratis.com.br/me4685.pdf. Acesso: 06 jun. 2019.

MACHADO, Geraldo Magela. Vygotsky. Disponível em: https://www.infoescola.com/biografias/vigots ki/. Acesso em: 03 maio 2019.

ROT'TA, Newra Tellechea; OHLWEILER, Lygia RIESGO; Rudimar dos Santos (Orgs.). Transtornos da aprendizagem: abordagem neurobiológica e Multidisciplinar. Disponível em:

file:// C:/Users/Usuario/Downloads/Transto rnos $\% 20 \mathrm{da} \% 20$ Aprendizagem-

Abordagem $\% 20$ neurobiol $\%$ C3 $\%$ B3 gica $\% 20 \mathrm{e} \%$ 20Multidisciplinar $\% 20$ -

$\% 20$ Newra $\% 20$ Tellechea $\% 20$ Rotta.pdf. Acesso: 30 abr. 2019.

SOUZA, Cirene Maria de. A compreensão da afetividade como elemento propulsor da melhoria do desempenho escolar - uma necessidade do saber docente, Disponível em: http://www.diaadiaeducacao.pr.gov.br/portals /cadernospde/pdebusca/producoes_pde/2014 $\angle 2014$ unioeste ped artigo_cirene maria_de s ouza.pdf. Acesso: 09 abr. 2019.

SPAGOLLA, Rosimeiri de Paula. Afetividade: por uma educação humanizada e humanizadora. Disponível

em: http://www.diaadiaeducacao.pr.gov.br/portals Lpde/arquivos/2343-8.pdf . Acesso em: 08 maio 2019.

SILVA, Erivânia Guedes da. Afetividade na pratica pedagógica e na formação docente. 
Disponível em:

https://monografias.brasilescola.uol.com.br/pe dagogia/a-afetividade-na-pratica-pedagogica-naformacao-docente.htm. Acesso: 7 jun. 2019. 